\title{
Process approach to waste management in Russia
}

\author{
Vera Beskrovnaya*, Anna Nazarova, and Roman Kolesnikov \\ Saint-Petersburg State University of Industrial Technologies and Design, 198095 Saint-Petersburg, \\ Russia
}

\begin{abstract}
The article is devoted to a relevant topic - formation of approaches to improving the management system of the process of handling solid municipal waste. An analysis of the available scientific sources allows us to conclude that there is a trend in the integration of project management and the concept of sustainable development in the Russian industry. On the basis of the process and design approaches, the authors have proposed a structural and functional model of the processes of handling solid municipal waste at the regional level, the result of which will be the transformation of part of the waste into secondary materials and energy resources.
\end{abstract}

\section{Introduction}

An analysis of the available scientific sources allows us to conclude that there is a trend in the integration of project management and the concept of sustainable development in the Russian industry. An analysis of approaches to assessing sustainability indicators showed a lack of consistency, as well as a shift in emphasis to individual indicators and insufficient attention to institutional indicators of sustainability. The problem is the lack of a methodology for quantifying the level of maturity of sustainable project management, which could form the basis for monitoring in waste management.

Hans Wiesmet, honorary professor of Faculty of Economics of Dresden University of Technology, in his article "Systemic change: the complexity of business in a circular economy", notes that the transition to a circular economy is often associated with business models that provide for the abandonment of the traditional concept of "lifespan" products in favor of finding new ways to use them and applying the principles of ecological design in the manufacturing of products. Such systemic changes are closely related to the hierarchy of priorities in waste management - the prevention of waste generation, recycling and reuse of goods, as well as the implementation of technological and organizational innovations for this. The article describes the challenges faced by companies in the context of the transition to a circular economy and illustrates their cases. The difficulties that arise are due to market mechanisms such as waste trading, emission quotas, and used products [1].

Particular attention is paid to the factor of the social rut, which is associated with the extraction of benefits as a result of decentralized decision-making by the subjects of the market economy. In the short term, a focused environmental policy will solve some of the

\footnotetext{
* Corresponding author: vabeskrovnaya@yandex.ru
} 
problems under consideration, but in the longer term, the social rut effect needs to be reoriented in order to successfully implement the circular principles.

It is interesting to note a number of researches done by scientists Christine Bidmon and Sebastian Knab, who explore the relationship between business model and transition theory, prove in their works that business models play three roles in transition societies, show how they affect transition processes as driving forces and obstacles and draw conclusions for a (sustainable) business model and transition studies [2].

The issue of analyzing the maturity of sustainable project management at Russian enterprises in the context of the transition to the digital economy is also relevant for our study. These questions were disclosed by S. Apenko and Yu. Fomina [3]. D.Yu. Savon, M.A. Abramov wrote the article which is devoted to the application of innovative methods of resource-saving in waste recycling and utilizing in the industrial sector [4]. The authors raise the issue of disposal and recycling of industrial waste, focusing on the fact that the problem is global. One of the innovative methods that allows people to analyze and generate positive dynamics is resource-saving. Conducting successful and effective activities in the field of resource-saving contributes to economic growth and increasing its competitiveness.

The topic of searching and analyzing existing approaches and tools for monitoring territorial development becomes relevant at the present stage of research. In Ferova I.S. and other scientists' researches, the main conceptual and methodological background that distinguishes the proposed approach is to take into account the effects of interregional and intersectoral interactions, in other words, the effects of cluster transfers [5].

It was revealed that among the authors of scientific works there is still no consensus not only on theoretical aspects, but also on methodological issues of the monitoring procedure and tools for assessing the sustainability of development, especially in the context of the cluster approach. The article provides an analysis of the main methodological approaches to assessing the sustainable development of multi-level systems (national and regional economies, territories, industries, enterprises and products). The systematization of approaches and tools used by scientists from different countries, as well as international organizations and institutions has been carried out.

Of particular interest is the use of SADT and ARIS methodologies for modeling and managing business processes. Researchers (Fedorova O.V., Mamaeva A.A., Yakunina E.A., and others) [6] carried out serious work on the analysis from both, the modeling business processes (notations) and using the CASE-tools point of view, and from the business process management point of view. The first point of view reflects the interaction between the business analyst and the IT engineer when developing an information system. The second point of view is the interaction between the business analyst and the customer.

An important aspect in the context of the given topic is the optimization of the main business processes of the enterprise in the ARIS methodology. Noteworthy is the article written by Abdullaev N.A. and Abdullaeva M.G. [7], which show specific examples of modeling business processes of an enterprise, give different recommendations for modeling business processes in ARIS Express modeling environment.

The regulatory aspect of the sustainable development concept plays an important part and was considered by E.I. Mayorova, and Temnova E.V. [8] The authors carried out a historical review of the incipience and development of the sustainable development concept, international regulatory documents reflecting decisions on changing the course of the entire world community from technogenic development to sustainable development. The authors noted that proposals on joint actions to promote the 'green economy' have contributed to the legislation of the Russian Federation: the Constitution of the Russian Federation contains 'Ecological' articles; adoption of the main environmental law - 'Environmental protection' law; the governing codes, which regulate the use of natural resources, contain rules that provide for environmental and legal liability. 
Russian experts concluded that the transition to sustainable development in each country and in the same country but at different times may have different priorities, which is reflected in the legislation. For example, the Russian Government approved the Strategy for Sustainable Development of Rural Areas of the Russian Federation for the period up to 2030. Currently, the legislation reflects the prevailing anthropocentric trends, but the authors hope for a change in the consumer worldview over time.

The formation of a municipal waste management model arouses interest when analyzing the process approach to recycling management (Sokolova O.G., Polezhaeva M.V., Chukhareva E.V.) [9]. The researchers propose to use positive foreign experience by taking into account the Russian regulations. Basing on systems, process, and logistic approaches, the authors propose the structural and functional model of the municipal waste management system, which will result in a reduction of the negative impact of waste on the environment by converting part of the waste into recycled materials and energy resources.

Popova L.F. discloses specifics of forming a quality management system based on the process approach in the industrial enterprises management [10]. The author considers the issues of building a process model of the quality management system, describes the nature and purport of the term 'process', systemizes the main approaches to the classification of processes, gives the author's understanding of the differences between business processes and quality management system processes. An analysis of the functioning of industrial enterprises using the example of the Saratov region made it possible to identify shortcomings in the identification of the used models of the quality management system and to identify processes that are not given sufficient attention.

Of particular interest are aspects of institutional reform in the field of waste management in the Russian Federation. Tagaeva T.O. and Gilmundinova V.M. consider the issues of the current environment state in the field of waste management, the authors developed different approaches for predicting the volume of waste generation and accumulation, allowing to assess the environmental load for the near future; the authors also analyze the main shortcomings of the ongoing reforms in this area [11].

According to A.V. Tolchenov, increasing the efficiency of domestic enterprises is impossible without the use of modern management technologies and information technologies that support them. The analysis carried out by the author is based on the object and process approaches and is supported by examples from practice [12].

Modern approaches to the interpretation of the concept of sustainable development should be taken into account when handling research. Starikov E.A. supplements and deepens existing researches, explains the terminological base and conceptual basis of sustainable development, identifies its current interpretations that best meet the needs of the global agenda [13]. The author comes to the conclusion that the triune concept of sustainable development is the most progressive, since it systematizes and covers other approaches. In this regard, the author emphasizes that global measures for the practical implementation of the goals and principles of the concept need to be taken.

The expressed views and opinions of Rachel Emasom (professor at Florida International University) [14] set out in the 'Vision for Sustainable Development: Definition and Guiding Principles' presented in a summary format for GSDR 2015 deserves special attention in the context of the research topic. 


\section{Research methodology}

When working on the research, a comparative content analysis of Russian and foreign literature was used. The SADT methodology served as the basis for studying the elements of modeling business processes in the waste processing environment.

\section{Research results}

All sources of waste generation can be divided into two large groups:

- Waste from production and consumption - this is the waste generated in the process of carrying out economic activities by enterprises, which can also be divided into sources of waste generation by type of economic activity.

- Solid municipal waste - this is the waste generated in the process of population consumption of goods and services. This also include goods that have lost their consumer properties in the process of their use by the population, bulky waste (furniture, household appliances, etc.), and some types of waste generated by legal entities and individual entrepreneurs.

Solid municipal waste is of the greatest interest for management purposes, since it has a significant impact on human health and the environmental situation, and also serves as a large source of secondary resources suitable for further processing. Detailed waste classification in Russia is determined according to the Federal Waste Classification Catalog approved by Order of Rosprirodnadzor dated May 22, 2017 No. 242 (as amended on November 2, 2018 No. 451).

The morphological composition of municipal solid waste differs depending on the climatic zone, season and source (residential areas or enterprises). The approximate morphological composition of solid municipal waste in Russia is shown in Figure 1.

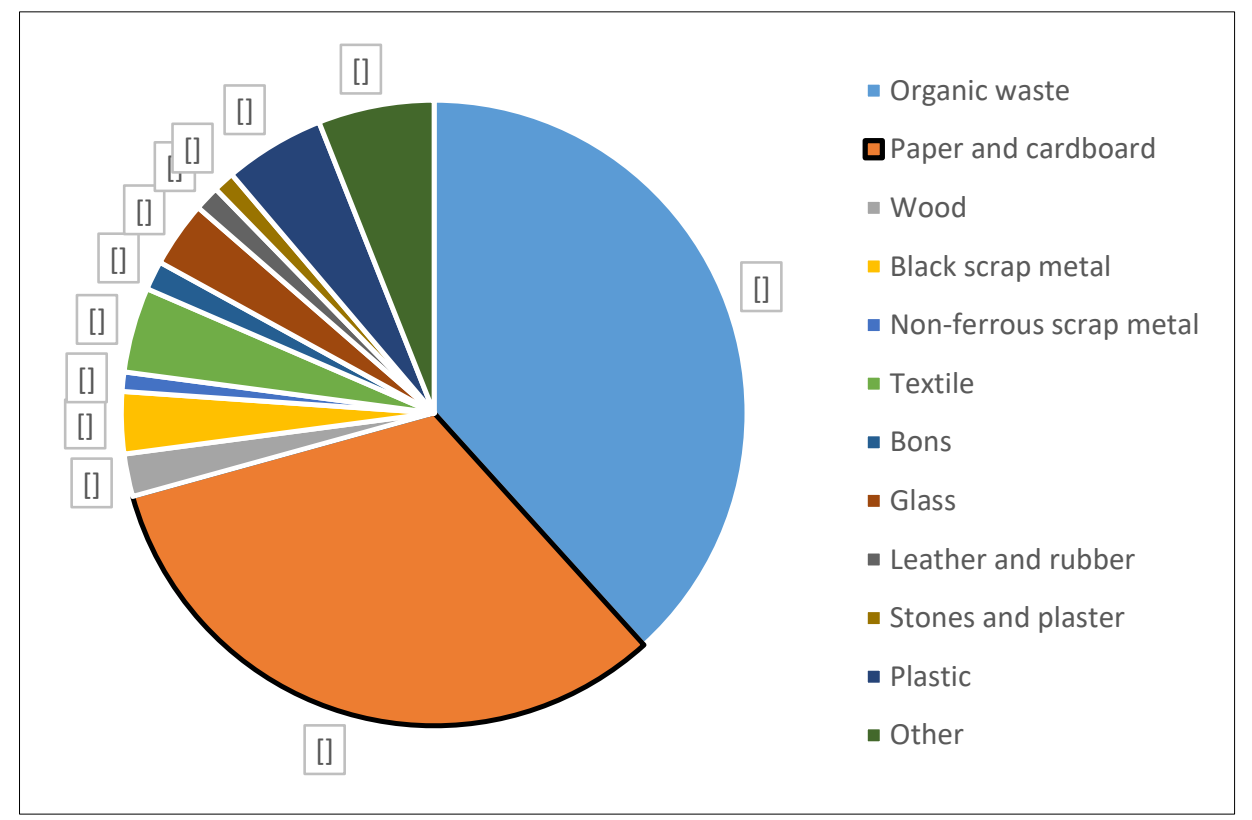

Fig. 1 Morphological composition of municipal solid waste in Russia.

Volumes of municipal solid waste taken out for further processing in Russia over the past 10 years shown in Figure 2. 


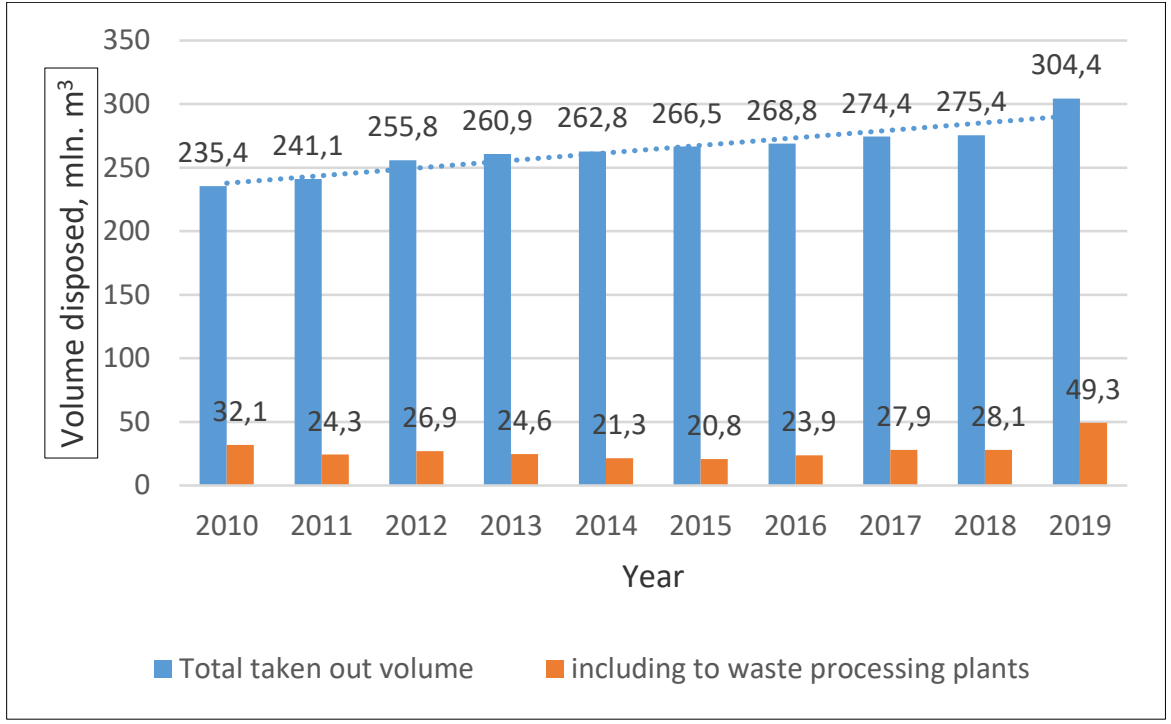

Fig. 2. Dynamics of solid municipal disposed in the Russian Federation in 2010-2019.

The volume of solid waste disposal in Russia in 2019 reached 304.4 million m3. The volume of municipal solid waste disposed in 2019, compared to 2010, increased by 69 million $\mathrm{m}^{3}$ or by $29 \%$. Approximately $16 \%$ of the total volume of disposed municipal solid waste (49.3 million $\mathrm{m}^{3}$ ) was sent to waste processing plants. The volume of waste disposed of at waste processing plants in 2019 , compared to 2010 , increased by $17.2 \mathrm{~m}^{3}$, or by $53.6 \%$.

There is a clear trend towards an increase in the volume of disposed municipal solid waste, growth rates of disposed municipal solid waste volume over the period of 2010-2019 is shown in the table 1.

Table 1. Increase in the volume of removed municipal solid waste in 2011-2019

\begin{tabular}{|c|c|c|c|c|c|c|c|c|}
\hline \multicolumn{10}{|c|}{ Growth rate, \% } \\
\hline 2011 & 2012 & 2013 & 2014 & $\mathbf{2 0 1 5}$ & $\mathbf{2 0 1 6}$ & $\mathbf{2 0 1 7}$ & $\mathbf{2 0 1 8}$ & $\mathbf{2 0 1 9}$ \\
\hline 2,42 & 6,1 & 1,99 & 0,73 & 1,41 & 0,86 & 2,08 & 0,36 & 10,53 \\
\hline \multicolumn{10}{|c|}{ Average growth rate for the period: $2,9 \%$} \\
\hline
\end{tabular}

The average annual increase in the volume of removed municipal solid waste amounted to 2.9 percentage points. The biggest increase was observed in 2019, compared to 2018, this is due to the launch of the so-called "Garbage" reform in Russia which has started from January 1, 2019, carried out within the framework of the national project "Ecology", which led to a more accurate accounting of the volumes of solid municipal waste disposal. Also, you can notice a sharp jump in the volume of municipal solid waste disposed of to waste processing plants from 28.1 million $\mathrm{m}^{3}$ in 2018 to 49.3 million $\mathrm{m}^{3}$ in 2019 , which is related to the active stage of preparation for the start of the reform and the construction of additional waste processing facilities in the regions.

The so-called "Garbage" reform in Russia is considered to be a set of measures taken by the government as part of the implementation of the national project "Ecology", which began in 2019 .

Table 2. Characteristics of the national project "Ecology" regarding waste management in the Russian Federation, 2019-2024. 


\begin{tabular}{|c|c|}
\hline \multicolumn{2}{|r|}{$\begin{array}{l}\text { The main goal of the national project "Ecology" in relation to waste: effective management of } \\
\text { production and consumption waste }\end{array}$} \\
\hline \multicolumn{2}{|r|}{$\begin{array}{l}\text { - elimination of all unauthorized landfills identified as of January 1, } 2018 \text { within city boundaries } \\
\text { (191 pcs.); }\end{array}$} \\
\hline & elimination of the most dangerous objects of accumulated environmental damage (75 pcs.); \\
\hline \multicolumn{2}{|r|}{$\begin{array}{l}\text { commissioning of industrial and technical complexes for the processing, utilization and disposa } \\
\text { of wastes of I and II hazard classes ( } 7 \text { units); }\end{array}$} \\
\hline & $\begin{array}{l}\text { an increase in the share of solid municipal waste sent for disposal in the total volume of } \\
\text { generated solid municipal waste }(36 \%) \text {; }\end{array}$ \\
\hline & $\begin{array}{l}\text { an increase in the share of municipal solid waste sent for further processing in the total } \\
\text { volume of municipal solid waste generated }(60 \%) \text {. }\end{array}$ \\
\hline \multicolumn{2}{|r|}{ To achieve these objectives and goals, there are several federal projects have been adopted: } \\
\hline & $\begin{array}{l}\text { "Reducing the negative impact on the environment by eliminating the most dangerous objects } \\
\text { of accumulated harm to the environment and unauthorized dumps within cities" ("Clean } \\
\text { Country") }\end{array}$ \\
\hline 2 & "Integrated system for the managen \\
\hline & \\
\hline
\end{tabular}

From the standpoint of managing the processing complex, it is also interesting to study the territorial distribution of the solid municipal waste disposal, the data is presented in Figure 3.

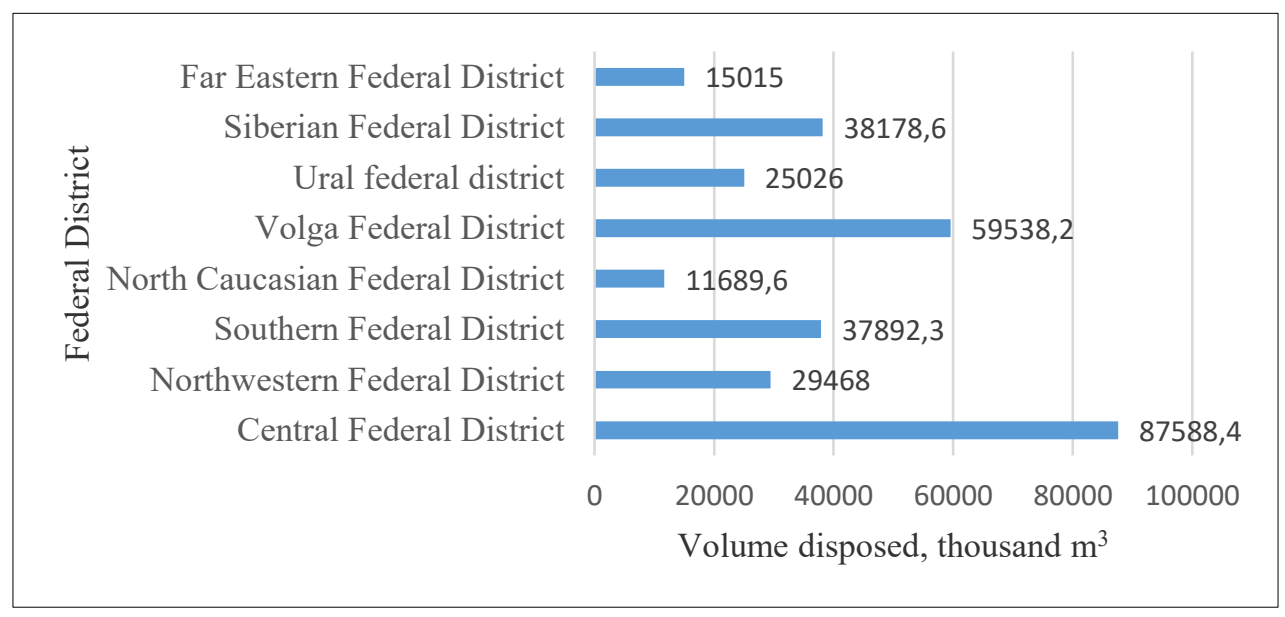

Fig. 3. Volumes of solid municipal waste disposed by federal districts of the Russian Federation in 2019.

The most volume of the solid municipal waste was disposed from the regions located in the central federal district $-87,588.4$ thousand $\mathrm{m}^{3}$. The least, from the regions belonging to the North Caucasian Federal District - 11689.6 thousand $\mathrm{m}^{3}$. This indicates a direct relationship between the size of the population living in the federal district and the amount of waste generated.

Collection of solid municipal waste in Russia is carried out mainly in a mixed way: waste is collected in containers without preliminary sorting. This method of waste collection significantly reduces the possibility of extracting high-quality secondary resources (textiles, paper, plastic, polymer waste and glass) for further recycling, due to their wetting and pollution. 
By the end of 2019, 18.2 million tons of waste were sent for processing, out of this number 2.7 million tons were sent for recycling. That is only about $15 \%$ of the waste sent for processing turned out to be suitable for recycling. If we rely on the average standard for the weight of $1 \mathrm{~m} 3$ of solid municipal waste equal to about $200 \mathrm{~kg}$, then only about $5 \%$ of the total volume of solid municipal waste generated in 2019 was sent for recycling.

\section{Results discussion}

The research has confirmed the need to streamline the processes of handling municipal solid waste at the regional level. It identified the weaknesses of the existing municipal solid waste management system, first of all, the lack of separate waste collection by the population. Based on the completed research, the following model of municipal solid waste management processes at the regional level can be proposed, presented in Figure 4.

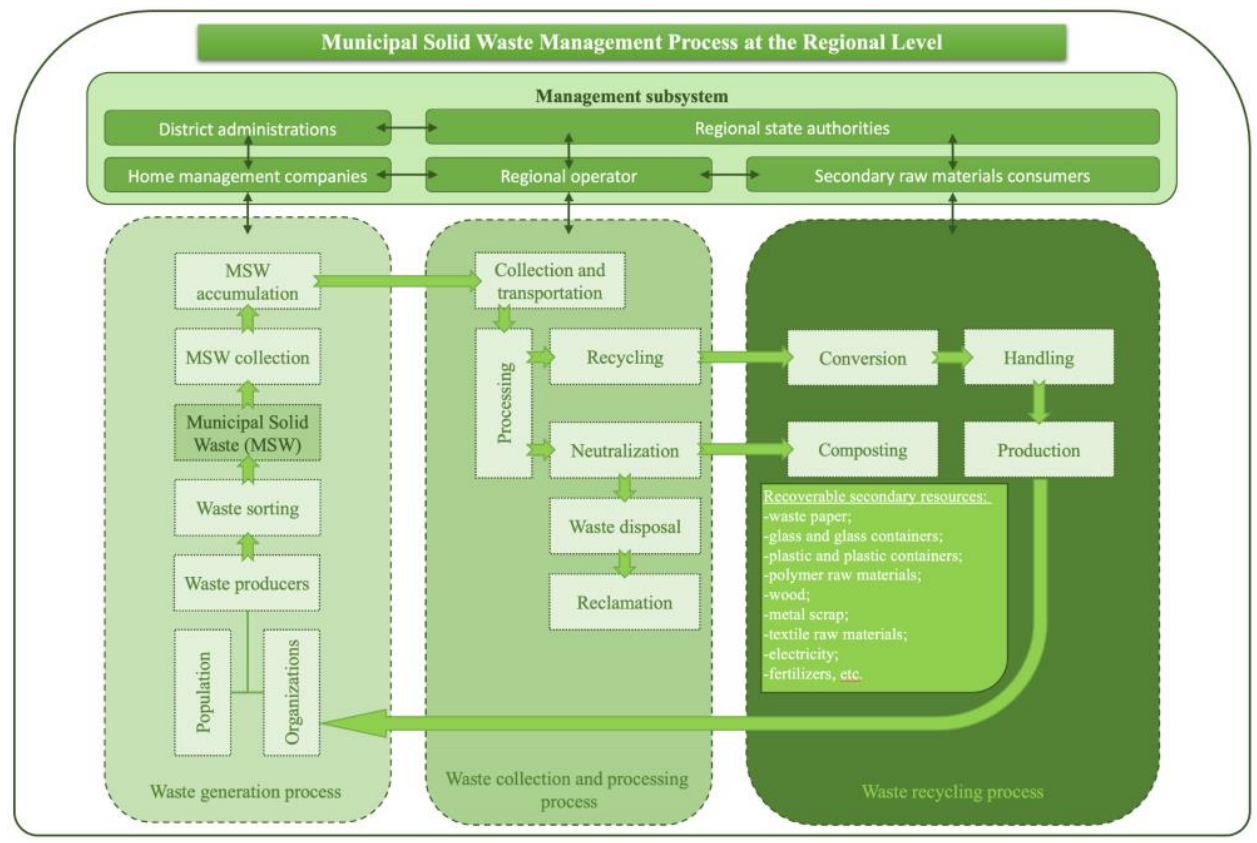

Fig. 4. Structural and functional model of municipal solid waste management processes at the regional level.

This model shows ordered groups of municipal solid waste management processes within a circular economy and includes the following groups of processes: waste generation, waste collection and processing, and waste recycling. Using the ARIS methodology, it is possible to show an enlarged sequence of individual processes of the municipal solid waste processing management system in a circular economy.

The ARIS system is a methodology for describing the internal structure and relationships of various business processes, and also denotes a software product intended for the development and visualization of such descriptions. The ARIS methodology, and the software product used for modeling business processes based on it, provides a wide visualization toolkit to ensure the visibility of the described models.

The key principle of the ARIS methodology is to consider any organization from five points of view: organizational, functional, processed data, structure of business processes, products and services. The ARIS methodology uses a special notation that includes the 
following elements: object, person (employee), role (group relation of employees to objects), events, activities (work), processes and risks.

The first step is to create a so-called processes map or processes structure, which shows an enlarged sequence of individual processes, shown in Figure 5.

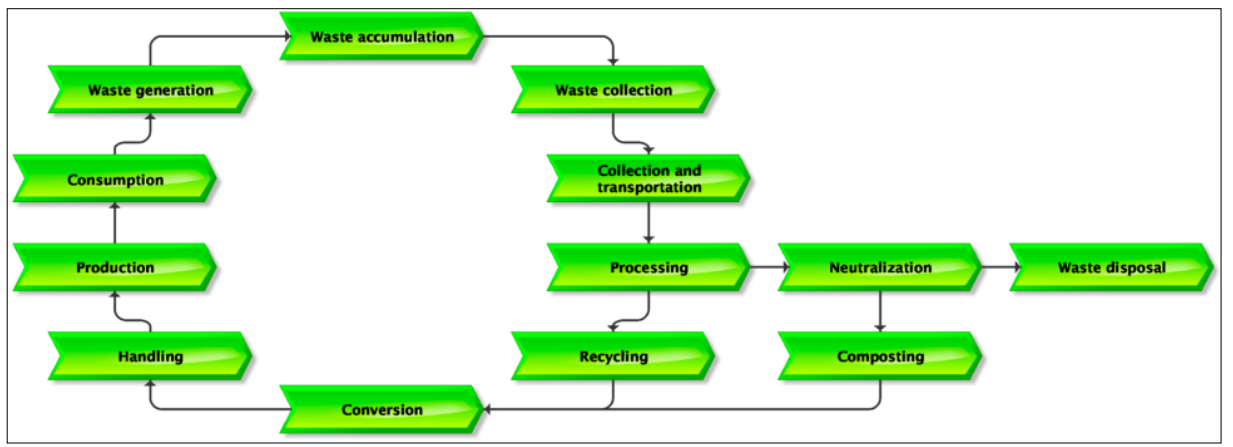

Fig. 5. Processes map of municipal solid waste management at the regional level

The next step is the decomposition of each individual process and its detailed specification. This method of graphical representation allows to describe in detail each individual business process, gives an understanding of the business process that precedes the current one, the event that led to the initiation of the business process, the event that marks the end of the current business process and the subsequent business process.

For the business process being decomposed, it is necessary to determine the incoming and outgoing documents that initiate the beginning and end of the business process, the software and databases used for this, the specific location of the function, and appoint the center of responsibility for the business process in question (organization or its subdivision).

This decomposition process can be continued to break down the process into separate steps that describe in detail the business process, appoint specific performers and responsible persons with reference to a geographic factor.

\section{Conclusion}

The conducted research allows us to conclude that currently there are tendencies for the integration of project management and the concept of sustainable development in the Russian municipal solid waste management system. Based on the process and project approaches, the authors proposed a structural-functional model of the processes of handling solid municipal waste at the regional level, which will result in the conversion of part of the waste into secondary materials and energy resources.

\section{References}

1. H. Wiesmeth, Foresight and STI Governance, 14(4), 47 (2020)

2. C.M. Bidmon, S.F. Knab, Journal of Cleaner Production, 178, 903 (2018)

3. S.N. Apenko, J.A. Fomina, Journal of Siberian Federal University. Humanities \& Social Sciences, 4(12),530 (2019)

4. D.Yu. Savon, M.A Abramova, Scientific Bulletin of the Moscow State Mining University, 276, (2015)

5. I. Ferova, E. Lobkova, E. Tanenkova and S. Kozlova, Journal of Siberian Federal University. Humanities \& Social Sciences, 4(12), 600 (2019) 
6. O. Fedorova, A. Mamaeva, E. Yakunina, Proceedings of VSUET, 80/1,105, (2018)

7. N.A. Abdullaev, M.G. Abdullaeva, Regional Problems of Economic Transformation, 3, 116 (2020)

8. E.I. Mayorova, E.V. Temnova, Management, 8(4), 94 (2020)

9. O.G. Sokolova, M.V. Polezhaeva, E.V. Chukhareva, STAGE: Economic Theory, Analysis, Practice, 3,130 (2019)

10. L.F. Popova, Perm University Herald. Economy, 12(3), 453 (2017)

11. T. Tagaeva, V. Gil'mundinov Journal of Siberian Federal University. Humanities \& Social Sciences, 13(4), 487 (2020)

12. A.V. Tolchenov, Bulletin of Saratov State Socio-Economic University, 3(27), 210 (2009)

13. E.A. Starikova, RUDN Journal of Economics, 25 (1), 7 (2017)

14. R. Emasom, The Concept of Sustainable Development: Definition and Defining Principles Brieffor GSDR (2015) 